\title{
The Contribution of the Three Columns of the Spine to Spinal Stability: A Biomechanical Model
}

\author{
T. R. Haher, MD,${ }^{1}$ J. M. Tozzi, MD,${ }^{1}$ M. F. Lospinuso, MD,${ }^{1}$ V. Devlin, \\ MD, ${ }^{1}$ M. O'Brien, MD, ${ }^{1}$ R. Tenant, $M D,{ }^{2}$ J. Ahmad, PhD,${ }^{3}$ J. Valenza, \\ $\mathrm{ME},{ }^{3}$ S. Parrish, $\mathrm{BE}^{3}$ \\ ${ }^{1}$ SUNY-HSC at Brooklyn, New York, USA, ${ }^{2}$ St Vincent's Hospital E Medical \\ Center, New York, USA, ${ }^{3}$ Cooper Union School of Engineering, New York, \\ USA.
}

\section{Summary}

The load carrying capacity (LCC) of the human spine was evaluated in 10 human cadaver spines. The specimens consisted of segments from T11 to S1 with markers placed on the specimens at each vertebral level in both Ap and lateral planes. The specimens were loaded to $1250 \mathrm{~N}$ and spinal deflections were recorded and photographed at $125 \mathrm{~N}$ intervals during the loading cycle. In 5 specimens, axial and flexion loads were applied to the intact spine. The anterior and middle columns were destroyed in sequence at L2 and the loading process repeated. In the remaining 5 specimens, axial and extension loads were applied with the spine intact and after the posterior and middle columns were destroyed in sequence at L2. Load deflection curves were generated for each test and comparisons were made between intact spines and spines with single and double column destruction. Results: When the axis of loading was anterior to the posterior longitudinal ligament (PLL), destruction of the anterior and middle columns reduced the LCC by $46 \%$ and $68 \%$ respectively and destruction of the posterior and middle columns reduced the LCC by $30 \%$ and $63 \%$ respectively. There was minimal change in the LCC when the axis of loading was posterior to the PLL and the anterior and middle columns were destroyed.

Two column destruction of the spine reduced its load carrying capacity for flexion loads by $70 \%$. In thoracolumbar spinal fractures where flexion loads are predominant and anticipated, the authors conclude that surgical stabilisation is indicated with double column failure.

Keywords: Spinal stability; Spinal columns; Load carrying capacity.

Definitions of spinal stability and indications for surgical stabilisation or brace containment of spinal injuries have varied over time (Burke and Murry, 1976;

Correspondence to: T. R. Haher, MD, Box 30, 450 Clarkson Ave, Brooklyn, New York 11203, USA.

Presented at the 23rd Annual Meeting of the Scoliosis Research Society. 
Denis, 1982; Frankel et al., 1969; Holdsworth, 1963; Jacobs et al., 1980). Although Hippocrates stated that all fractures should be anatomically reduced, with many spinal fractures anatomical reduction and surgical stabilisation are not necessary and the results of such treatment may be worse than the subsequent untreated spinal deformity. Numerous classification schemes and indications for surgical treatment of spinal fractures have been published to date. These classifications however usually have been based on supine roentgenograms of the injured spine (Bedbrook and Edibaum, 1973; Holdsworth, 1963; Leidholdt et al., 1969; Nicoll, 1949; Riggins and Kraus, 1977) or on anatomical dissections of intact cadaveric spines (Rissanen, 1960; White and Panjabi, 1978; White et al., 1981). Indications for operative intervention have varied with each classification system and often have been based on the long term follow-up of patients with non-operatively treated fractures (Bohlmann, 1976; Burke and Murry, 1976; Lewis and McKibbin, 1974; Malcolm, 1979; Nicoll, 1949; Roberts and Curtiss, 1970; Young, 1973) or on arbitrary predetermined measurements from supine films (Bedbrook and Edibaum, 1973; Denis, 1982; Morris et al., 1961; Rissanen, 1960). With the advent of the three column classification of spinal anatomy a more precise analysis of spinal stability was made possible (Denis, 1982, 1984; McAfee et al., 1982). Knowing which columns are intact can better enable the clinician to interpret the integrity of the spine as a loadbearing column. An understanding of the contribution of each column to overall stability would greatly enhance our understanding of the unstable spine.

\section{Materials and methods}

Ten spines were harvested by the authors from autopsy specimens. The specimens consisted of intact spines from $\mathrm{C} 1$ to $\mathrm{S} 1$. The specimens had no intrinsic deformities and were frozen at $-20^{\circ} \mathrm{C}$ until testing. The age, sex, cause of death, and general health of the donors were known. The paravertebral musculature was dissected from the specimens at the time of testing. The spines were transected through the vertebral bodies at the level of T11 and S1 and thawed to room temperature. The planes of transection were parallel at the end plates and were perpendicular to the long axis of the spine. The specimens were placed between the stationary and mobile plates of a Tinius-Olsen Super ' $L$ ' UTM (Tinius Olsen Testing Machine Company, Pa, USA). A deflection gauge $(0.01 \mathrm{~mm}$ increments) was placed on the mobile plate. Compressive loads and corresponding deflections were recorded. Flexion and extension were added to the normal sagittal curves of the spine by angulation of the superior load plate and measured using a goniometer. Lateral photographs were taken of the specimens at $125 \mathrm{~N}$ increments in the loading and unloading phase. Each specimen was loaded to $1250 \mathrm{~N}$ over time periods of 3 minutes. The loading cycle was repeated 3 times. A 10-minute recovery time was used between each loading cycle. The specimens were unloaded and similar data was recorded. Each specimen was loaded according to the scheme in Tables I and II.

The specimens were divided into 2 groups of 5 each. The first 5 specimens were tested intact with the loads applied axially and in 20 degrees of flexion (Fig. 1A and B). The anterior column was then destroyed at L2 including the anterior longitudinal ligament, the anterior aspect of the vertebral body and the 
Table I Loading scheme of spines in flexion

\begin{tabular}{ll}
\hline Spine & Load \\
Intact & $\begin{array}{l}\text { Axiel } \\
\text { Flexion }\end{array}$ \\
& Axial \\
Flexion & Anterior column \\
& $\begin{array}{l}\text { Axial } \\
\text { Flexion }\end{array}$ \\
\hline
\end{tabular}

Table II Loading scheme of five spines in extension

\begin{tabular}{ll}
\hline Spine & Load \\
Intact & Axiel \\
& Extension \\
& Axial \\
$(-)$ Posterior column & Extenson \\
& Axial \\
(-) Poterior and middle & Extension \\
\hline
\end{tabular}

anterior aspect of the disc (Fig. 1C). The specimens were again loaded axially and in flexion. The middle column was then destroyed at the same level including the posterior aspect of the disc, posterior vertebral body and the posterior longitudinal ligament and loaded in similar fashion (Fig. 1D). The next 5 specimens were loaded axially and in extension. The specimens were loaded with all three columns inact, after destruction of the posterior column (Fig. 1D) and finally with the destruction of the posterior and middle columns (Fig. 1E).

The data was plotted with the axes load vs. deflection (Fig. 2). The load needed to achieve a specific deflection was found. The stiffness $(N)$ of the specimen was calculated from the tangent slope of the load deflection curve at a given deflection. The effects of column destruction are apparent when the load deflection curves are superimposed (Fig. 3).

The loading carrying capacity (LCC) of the spine was calculated for each test by using the following formula:

$$
\mathrm{LCC}=\frac{\mathrm{L}_{\text {Spit iu Def.-Col }}}{\mathrm{L}_{\text {Spt } a \text { Def. Intact }}} \times 100
$$

where $\mathrm{L}$ is defined as the load needed to achieve a specific deformation: $\mathrm{Sp}$ (\#) represents the specific spine being tested: (- Col) represents the column that has been destroyed: LCC is defined as the ability of the spine to support a given load as compared to the intact specimen. An intact spine is defined as having an LCC of $100^{\circ}$.

The amount of load needed for a given deformation between intact and compromised specimens was compared and their ratio calculated. The LCC was calculated for each spine with respect to its method of loading and the number 

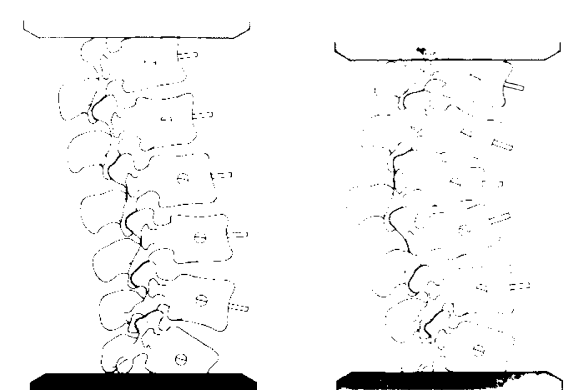

A

B
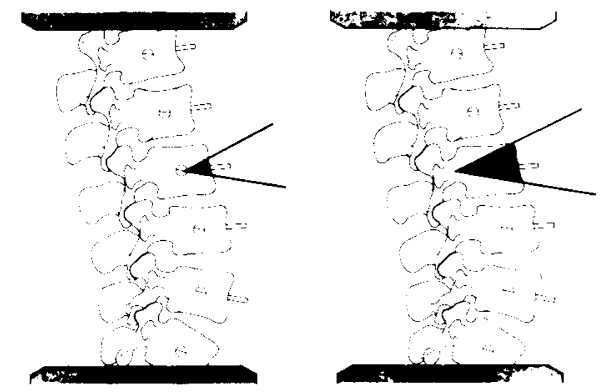

$\mathrm{D}$
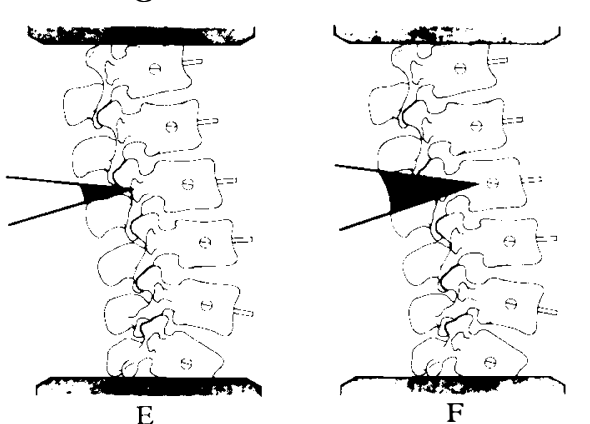

Figure 1 Diagrammatic representation of the sequential column destruction of the spines. 1A: Intact spine T12-L5 with normal sagittal plane maintained. 1B: Intact spine in $20^{\circ}$ of flexion. 1C: Destruction of the anterior column. 1D: Destruction of the anterior and middle column. 1C: Destruction of the posterior column. 1F: Destruction of the posterior and middle column.

of columns destroyed (Table III). The average values of the LCC for all groups and methods of loading are shown in Table IV.

\section{Results}

The LCC of the spine is a function of the number of intact columns. Table III represents the effect of the comprised columns on the LCC of the spine. The average values for a given column defect is shown in Table IV. With isolated destruction of the anterior or posterior columns, one could expect a loss in the LCC of $22 \%$. The loss of the LCC increases with flexion in an anteriorly compromised spine, and with extension with a posteriorly compromised spine. The LCC decreased an additional $24 \%$ with flexion in the specimen with anterior column destruction and by an additional $8 \%$ with extension in the 


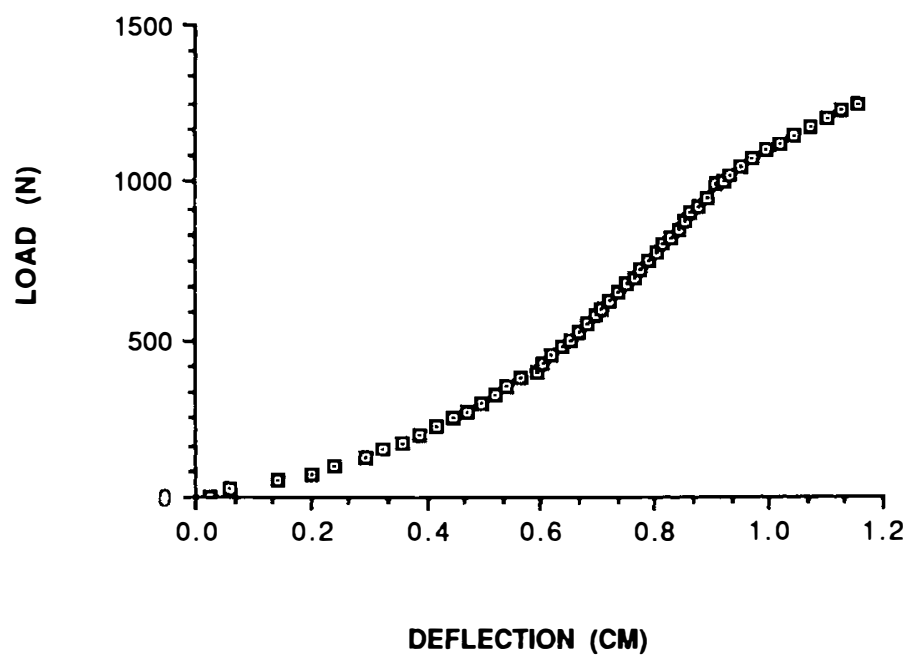

Figure 2 Load deflection curve: Applied load plotted against the deflection of the spine. SP6.3 load time 4:09:00.

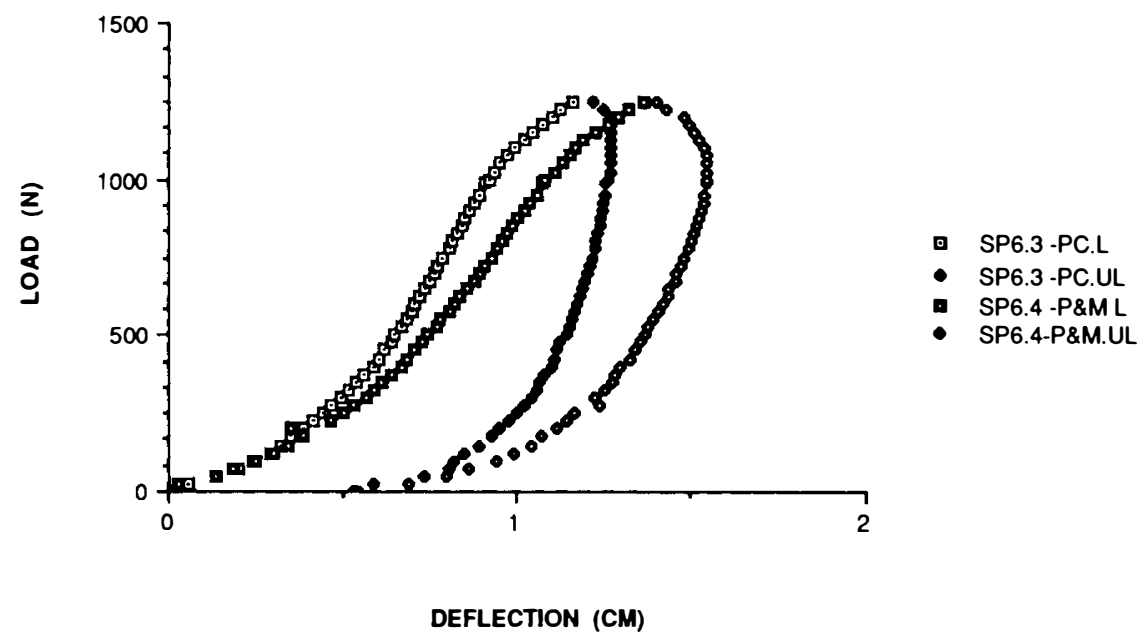

Figure 3 Overlay plot from intact and compromised curves showing effect of column destruction on the ability of the spine to support a load at a given deflection. Curves represent the loading and unloading cycles of a specimen with posterior column destruction compared with the same specimen with posterior and middle destruction. SP6.3-PC.L (Spine 6 with destruction of the posterior column in loading). SP6.4-P\&M.L (Spine 6 with destruction of the posterior and middle columns in loading.)

specimen with loss of the posterior column. The LCC decreased with multiple column failure. The LCC decreased $70^{\circ}$ o with anterior and middle destruction in flexion. This represented a $6.5 \%$ increase as compared to axial loading. With posterior and middle column destruction the LCC decreases to $40 \%$. When tested in extension the loss of the LCC was $65 \%$. All LCC values are dependent upon the true loading axis. The loading of the specimen and the assumed loading axis were analysed in conjunction with the photographs taken at $125 \mathrm{~N}$ intervals during loading. This would assure proper loading technique. Adding flexion or extension to the specimen further decreased the LCC. This was 
Table III Load carrying capacity of spines measured at a specific deflection. Column; designates the columns destroyed and the mode of loading (Axial, flexion and extension). Load in newtons. LCC; Load carrying capacity. N; stiffness of the specimen. Time; the time for the loading cycle.

\begin{tabular}{|c|c|c|c|c|}
\hline \multicolumn{5}{|c|}{ Load carrying capacity } \\
\hline Column & $\operatorname{Load}(\mathrm{N})$ & $\operatorname{LCC}\left({ }^{0} 0\right)$ & $\mathrm{N}$ & Time \\
\hline \multicolumn{5}{|c|}{ Loads measured at deflection of $1.27 \mathrm{~cm}$} \\
\hline Intact axial & 1110 & 100 & $0 \cdot 57$ & $3: 30$ \\
\hline Intact (flex) & 1110 & 100 & $0 \cdot 25$ & $3: 40$ \\
\hline (-) Ant col (ax) & 557 & 50 & $0 \cdot 31$ & $2: 50$ \\
\hline (-) Ant flex & 532 & 48 & $0 \cdot 24$ & $3: 10$ \\
\hline$(-) A \& M(a x)$ & 333 & 30 & $0 \cdot 21$ & $3: 35$ \\
\hline (-) A \& M (flex) & 400 & 35 & $0 \cdot 33$ & $3: 00$ \\
\hline \multicolumn{5}{|c|}{ Spine 2 Loads measured at deflection of $0.4 \mathrm{~cm}$} \\
\hline Intact (axial) & 622 & 100 & $2 \cdot 0$ & $2: 55$ \\
\hline Intact (flex) & 620 & 100 & 1.9 & $2: 50$ \\
\hline$(-)$ Ant col $(a x)$ & 555 & 90 & $1 \cdot 7$ & $3: 10$ \\
\hline (-) Ant col (flex) & 440 & 70 & 1.5 & $4: 40$ \\
\hline$(-) A \& M \operatorname{col}(a x)$ & 178 & 30 & $0 \cdot 26$ & $4: 46$ \\
\hline$(-) A \& M \operatorname{col}(\mathrm{fl})$ & 111 & 17 & $0 \cdot 34$ & $2: 57$ \\
\hline \multicolumn{5}{|c|}{ Spine 3 Loads measured at deflection of $0.6 \mathrm{~cm}$} \\
\hline Intact (axial) & 888 & 100 & $0 \cdot 8$ & $3: 00$ \\
\hline Intact (flex) & 820 & 93 & $0 \cdot 7$ & $3: 30$ \\
\hline (-) Ant $\operatorname{col}(\mathbf{a x})$ & 700 & 80 & $0 \cdot 5$ & $2: 50$ \\
\hline (-) Ant col (flex) & 640 & 72 & $0 \cdot 51$ & $3: 00$ \\
\hline$(-) \mathrm{A} \& \mathrm{M} \operatorname{col}(\mathrm{ax})$ & 577 & 65 & $0 \cdot 61$ & $4: 00$ \\
\hline$(-) \mathrm{A} \& \mathrm{M} \operatorname{col}(\mathrm{fl})$ & 532 & 60 & 0.65 & $3: 30$ \\
\hline \multicolumn{5}{|c|}{ Spine $4 \quad$ Loads measured at deflection of $0.9 \mathrm{~cm}$} \\
\hline Intact (axial) & 1110 & 100 & $0 \cdot 81$ & $3: 30$ \\
\hline Intact (flex) & 1065 & 95 & $0 \cdot 80$ & 3:00 \\
\hline$(-)$ Ant col (ax) & 999 & 90 & $0 \cdot 72$ & $4: 30$ \\
\hline$(-) A \& M \operatorname{col}(a x)$ & 300 & 30 & 0.32 & $2: 30$ \\
\hline \multicolumn{5}{|c|}{ Spine $5 \quad$ Loads measured at deflection of $0.76 \mathrm{~cm}$} \\
\hline Intact (axial) & 1000 & 100 & $2 \cdot 0$ & $5: 04$ \\
\hline Intact (flex) & 888 & 88 & $2 \cdot 0$ & $5: 70$ \\
\hline (-) Ant col (ax) & 540 & 54 & $1 \cdot 2$ & $4: 00$ \\
\hline (-) Ant col (flex) & 440 & 44 & $0 \cdot 5$ & $4: 30$ \\
\hline (-) A \& M col (f) & 177 & 17 & $0 \cdot 8$ & $3: 30$ \\
\hline \multicolumn{5}{|c|}{ Loads measured at a deflection of $1.0 \mathrm{~cm}$} \\
\hline Intact (axial) & 1110 & 100 & $0 \cdot 77$ & $3: 24$ \\
\hline (-) Posterior col & 900 & 81 & 0.65 & 4:09 \\
\hline (-) Post \& mid & 420 & 40 & 0.53 & $3: 45$ \\
\hline \multicolumn{5}{|c|}{ Spine $7 \quad$ Loads measured at a deflection of $0.653 \mathrm{~cm}$} \\
\hline Intact (axial) & 1200 & 100 & 0.92 & $5: 19$ \\
\hline (-) Posterior col & 1021 & 85 & $0 \cdot 90$ & $2: 20$ \\
\hline (-) Post \& mid col & 666 & 55 & $0 \cdot 84$ & $2: 41$ \\
\hline$(-)$ Post \& mid (ext) & 440 & 37 & 0.71 & $2: 10$ \\
\hline \multicolumn{5}{|c|}{ Spine $8 \quad$ Loads measured at a deflection of $0.76 \mathrm{~cm}$} \\
\hline Intact (axial) & 800 & 100 & $0 \cdot 82$ & $4: 50$ \\
\hline Intact (ext) & 710 & 89 & 0.55 & $5: 17$ \\
\hline (-) Posterior & 754 & 94 & $0 \cdot 83$ & $4: 40$ \\
\hline (-) Post (ext) & 666 & 83 & $0 \cdot 56$ & $3: 49$ \\
\hline (-) Post \& mid (ax) & 577 & 72 & $0 \cdot 83$ & $3: 23$ \\
\hline (-) Post \& mid (ext) & 300 & 31 & 0.53 & $2: 51$ \\
\hline \multicolumn{5}{|c|}{ Spine $9 \quad$ Loads measured at a deflection of $0.5 \mathrm{~cm}$} \\
\hline Intact (axial) & 667 & 100 & 0.95 & $2: 45$ \\
\hline (-) Posterior (ax) & 444 & 66 & $0 \cdot 84$ & $2: 04$ \\
\hline (-) Post \& mid (ax) & 448 & 73 & $0 \cdot 80$ & 3:00 \\
\hline (-) Post \& mid (ext) & 266 & 40 & $0 \cdot 52$ & $1: 45$ \\
\hline \multicolumn{5}{|c|}{ Spine $10 \quad$ Loads measured at a deflection of $0.65 \mathrm{~cm}$} \\
\hline Intact (axial) & 843 & 100 & 0.6 & $3: 50$ \\
\hline (-) Post (ext) & 532 & 63 & 0.56 & $4: 20$ \\
\hline (-) Post \& mid (ext) & 310 & 36 & $0 \cdot 30$ & $3: 40$ \\
\hline
\end{tabular}


Table IV Average load carrying capacities (LCC) and the loss of the LCC for that specimen

\begin{tabular}{llll}
\hline Average LCC values & Load & $\operatorname{LCC}\left({ }^{0}, 0\right)$ & $\operatorname{Loss}$ of $\operatorname{LCC}\left({ }_{0}{ }_{0}\right)$ \\
\hline Column & Axial & $77 \cdot 5$ & $22 \cdot 5$ \\
(-) Anterior & Flexion & $54 \cdot 0$ & $46 \cdot 0$ \\
(-) Anterior & Axial & $38 \cdot 8$ & $61 \cdot 2$ \\
(-) Anterior and Middle & Flexion & $32 \cdot 3$ & $67 \cdot 7$ \\
(-) Anterior and Middle & & & \\
& Axial & $77 \cdot 6$ & $22 \cdot 4$ \\
(-) Posterior & Extension & $70 \cdot 0$ & $30 \cdot 0$ \\
$(-)$ Posterior & Axial & $61 \cdot 6$ & $38 \cdot 4$ \\
(-) Posterior and Middle & Extension & $36 \cdot 8$ & $63 \cdot 2$ \\
\hline
\end{tabular}

evident in both the intact and compromised spine (Table IV). The stiffness (N) of the specimens decreased with column destruction. The decrease in stiffness was proportional to the number of columns destroyed.

\section{Discussion}

The indications for surgery of the injured or compromised spine are often based upon the supine (unloaded) roentgenograms. It is difficult or even impossible to predict the load carrying capability of that spine based on X-rays that neither reflect the character of the spine at the moment of injury, nor represent the spine in the loaded or physiological situation. Each portion or column of the spine contributes a strength to the overall intact spine. In assigning a ielative strength to each part of the spine, a predicted or resultant strength could be calculated by a summation of those parts that are compromised.

Table III contains the results of the Load deflection curves for each specimen. The capability of the specimen to support a given load decreased as the number of columns were destroyed. This effect was most significant with the destruction of the anterior and middle columns and was augmented when the axis of loading was placed over the compromised column or columns. The data compares favourably with the work of Tenser and Mayer (1983) concerning the major load-bearing elements of the spine. The stiffness of the specimens decreased with single and multiple column destruction.

The average stiffness was larger in flexion than in extension when compared to the intact specimen. This finding is presumably due to the increased load carrying capacity of the anterior column (Edward et al., 1987).

\section{Conclusion}

An attempt has been made to quantitatively analyse the contribution of each column of the spine to overall stability. The anterior and posterior columns individually are responsible for $22^{\circ} \%$ of the load carrying capacity of the spine under axial loading. With flexion and extension, the Loss of the LCC increases to $46 \%$ and $30 \%$ respectively. The anterior and middle columns combined are responsible for $68 \%$ of the load carrying capability (LCC) of the spine with flexion. The posterior and middle columns combined contribute $63 \%$ of the 
LCC with extension. The true axis of loading and the rate of loading must be known before any load deflection data can be interpreted.

\section{References}

Bedbrook GM, Edibaum RC 1973 The study of spinal deformity in traumatic spinal paralysis. Paraplegia 10:321.

BoHLMAN HH 1976 Late progressive paralysis and pain following fractures of the thoracolumbar spine. In Proceedings of the American Academy of Orthopaedic Surgeons. Fournal of Bone and foint Surgery 58A:728.

BRADFORD DS 1978 Role of internal fixation and spine fusion in thoracic and lumbar fractures. In: Chou, Seljeskog (eds) Spinal Deformities and Neurological Dysfunction. Raven Press, New York, pp. 155-173.

BROBERG KB 1983 On the mechanical behavior of intervertebral discs. Spine 8:151-165.

BURKE DC, MURRY DD 1976 The management of thoracic and thoraco-lumbar injuries of the spine with neurological involvement. Fournal of Bone and foint Surgery 58B:72.

DENIS F 1982 Updated Classification of thoraco-lumbar fractures. 6:8-9.

DENIS F 1984 Spinal instability as defined by the three column spine concept in acute spinal trauma. Clinical Orthopaedics and Related Research 189:65-76.

EDWARD WT, HAYES WC, POSNER I, et al. 1987 Variation of lumbar spine stiffness with load. Fournal of Biomechanical Engineering 109:35-42.

FRANKel HL, HaNCOCK DO, Hyslop G, et al. 1969 The value of postural reduction in the initial management of closed injuries of the spine with paraplegia and tetraplegia, part 1. Paraplegia 7:179-192.

HolDswORTH FW 1963 Fractures, dislocations and fracture-dislocations of the spine. Fournal of Bone and foint Surgery 45B:6.

JACOBS RR, AsHer MA, SNIDER RK 1980 Thoracolumbar Spine injuries. A comparative study of recumbent and operative treatment in 100 patients. Spine 5:493-497.

KAUfER H, HAYES JTY 1966 Lumbar fracture-dislocations. A study of twenty one cases. Fournal of Bone and foint Surgery 48a:712-730.

LEIDHOLDT JD, et al. 1969 Evaluation of late spinal deformities with fracture dislocations of the dorsal and lumbar spine in paraplegias. Paraplegia 7:16.

Lewis J, McKibin B 1974 The treatment of unstable fracture dislocations of the thoraco-lumbar spine accompanied by paraplegia. Fournal of Bone and foint Surgery 56B:603.

MCAFEe PC, YuAN HA, LASDA NA 1982 The unstable burst fracture. Spine 7:365-373

MALCOLM BW 1979 Spinal deformity secondary to spinal injury. Orthopedic Clinics of North America 10:943-952.

Morris JM, LuCAS DB, BRESLER B 1961. The role of trunk in stability of the spine. fournal of Bone and foint Surgery 42A:327.

NicOLL EA 1949 Fractures of the dorso-lumbar spine. Fournal of Bone and foint Surgery 31B:376.

RIGGINS RS, KRAUS JF 1977 The risk of neurological damage with fractures of the vertebra. fournal of Trauma 17:126.

RISSANEN P 1960 The surgical anatomy and pathology of the supraspinous and interspinous ligaments of the lumbar spine with special reference to ligament ruptures. Acta Orthopaedica Scandinavica 46.

RoAF R 1960 A study of the mechanics of spine injuries. Fournal of Bone and foint Surgery 42B:810.

ROBERTS JB, CURTISS PH 1970 Stability of the thoracic and lumbar spine in traumatic paraplegia following fracture dislocation. Fournal of Bone and foint Surgery 52A: 1115-1130.

Sullivan JD, Farfan HF 1975 The crumpled neural arch. Orthopedic Clinics of North America 6:199.

Tenser AF, MAYer TG 1983 Soft Tissue Strain and Facet Face Interaction in the Lumbar Intervertebral Joint. Fournal of Biomechanical Engineering 105:201-250.

White AA III, Panjabi MM 1978 Clinical Biomechanics of the Spine. Lippincott, Philadelphia.

White AA III, et al. 1981 Spinal stability: evaluation and treatment. Institute Course Lecture 30:457-483.

Whitesides TE, SHAH SGA 1976 On the management of unstable fractures of the thoracolumbar spine; rationale for use of anterior decompression and fusion and fusion and posterior stabilization. Spine 1:99.

YounG MH 1973 Long term consequences of stable fractures of the thoracic and lumbar vertebral bodies. Fournal of Bone and foint Surgery 55B:295. 